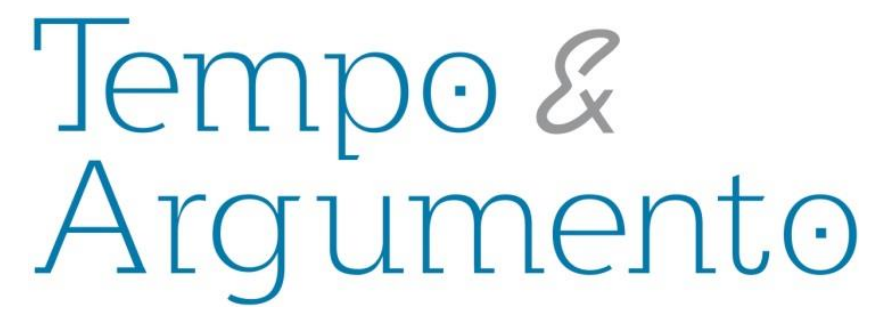

\title{
O fim da história e o fardo da temporalidade
}

\begin{abstract}
Resumo
O presente ensaio busca, a partir principalmente das obras de Hayden White e Fredric Jameson, discutir as noções de "fardo de história" e "fim da temporalidade", confrontando-as tanto com a atual conjuntura política e a vida sob a égide do neoliberalismo quanto com os problemas que parecem açodar a historiografia disciplinada. $O$ argumento principal do texto é o de que esses problemas não dizem respeito somente a questões teóricometodológicas internas à disciplina, mas também a mudanças mais profundas na ordem temporal que the deu origem e que qualquer tentativa de repensar a historiografia para a nossa época deve confrontar suas próprias políticas do tempo histórico.
\end{abstract}

Palavras-chave: Temporalidade. História. Historiografia.

\section{Arthur Lima de Avila}

Doutor em História pela Universidade Federal do Rio Grande do Sul (UFRGS). Professor na Universidade Federal do Rio Grande do Sul (UFRGS).

Porto Alegre - RS - Brasil arthurlavila@gmail.com

\section{Para citar este artigo:}

AVILA, Arthur Lima. O fim da história e o fardo da temporalidade. Tempo e Argumento, Florianópolis, v. 10, n. 25, p. 243 - 266, jul./set. 2018. 


\title{
The end of history and the burden of temporality
}

\begin{abstract}
The present essay aims, from the standpoint provided by the works of Hayden White e Fredric Jameson, to discuss the notions of "the burden of history" and "the end of temporality", by confronting them both with our current political conjuncture and with life under neoliberalism as well with the problems that seem to plague disciplined historiography. The main argument of the text is that these problems do not solely concern theoretical and methodological questions internal to the discipline, but also concern deeper changes in the temporal order that gave it birth and that any attempt to rethink historiography to our age must confront its own politics of historical time.
\end{abstract}

Keywords: Temporality. History. Historiography.

O final da história? O final do homem? É sério pensar nisso? São acontecimentos longínquos que a Ansiedade - ávida de desastres iminentes - deseja a todo custo precipitar.

(CIORAN, 2011, p. 99)

One is responsible to life: it is the small beacon in that terrifying darkness from which we come and to which we shall return. One must negotiate this passage as nobly as possible, for the sake of those who are coming after us.

(BALDWIN, 1993, p. 92)

Em 1963, refletindo sobre o violento racismo estrutural dos Estados Unidos, James Baldwin, uma das maiores inteligências norte-americanas do século XX, argumentou que isso, em parte, derivava da falha contumaz de seus compatriotas brancos em confrontar o horror do passado escravocrata de seu país. Para ele, esse fracasso equivalia a uma enorme repressão que chancelava uma pretensa inocência legitimadora dos linchamentos, torturas e sevícias sofridos pelos afro-americanos. Enquanto não ocorresse 

nomeado e afrontado, para que dela nascesse uma imaginação capaz de transcendê-la: uma vez abandonados os medos do que a vida poderia trazer, qualquer coisa que ela trouxesse, segundo ele, poderia ser enfrentada. Não existiria outra forma de se resolver o "problema da história" numa era que havia desnudado a extensão da capacidade dos seres humanos em infligir horrores inomináveis aos seus próximos.

Os questionamentos de Baldwin revelam, assim, uma inquietação política importante e que mantém uma atualidade fundamental: como podemos usar os diversos passados que acossam nossos presentes sem, contudo, afogarmo-nos neles? Em outros termos: de que forma podemos, se é que podemos, construir histórias que nos permitam uma libertação mínima diante daquilo que fomos forçados a herdar, quando não a suportar? Quais imaginações, finalmente, podem nos ser importantes para que, nas palavras de Baldwin (2005, p. 81), "tais passados desonrosos não voltem para nos esmagar"?

Essas questões são similares àquelas colocadas por Hayden White em seu afamado ensaio "O Fardo da História", originalmente publicado em 1966 - na mesma conjuntura que animou seu conterrâneo Baldwin. No entanto, ao contrário deste, o alvo de White naquele texto era a historiografia disciplinada e sua incapacidade, por causa de sua obsessão em tornar-se "científica", em colaborar para a "construção de perspectivas" que oferecessem soluções aos problemas peculiares de seu tempo. De acordo com ele, a "tática fabiana" comumente utilizada por historiadores e historiadoras para se justificarem diante das críticas de artistas e cientistas não só era insatisfatória teoricamente, como o era politicamente; ao construírem interpretações que privilegiavam o "passado em si mesmo", algo análogo a uma "necrofilia cultural”, seus e suas colegas abdicavam de propor imaginações que colaborassem para a libertação dos seres humanos do "fardo da história". O passado disciplinado era um passado morto, objetificado e impossível de ser usado do modo como Baldwin, por exemplo, pensou ser necessário para a construção de futuros diferentes daquele presente. Não era de se 
Cinco décadas depois, as admoestações de Baldwin e White mantêm sua urgência, ainda que não pelos mesmos motivos que as animaram inicialmente. Se naquele contexto, o problema fundamental era a construção do futuro, agora ele parece ser sua imaginação mesma; dito de outra maneira, nesses últimos cinquenta anos, a crença na história que, de um modo ou de outro, sustentava ambas intervenções, foi subjugada por um presentismo rampante ou, na expressão de François Hartog, "monstruoso". Na nossa era de "reestruturação capitalista", "fim do comunismo", "globalização neoliberal” e “transição pós-fordista” (ELEY, 2011, p. 557), a aceleração do modo de produção capitalista andou de mãos dadas com a aparente obsolescência das (ditas) grandes narrativas iluministas, por um lado, e com a obsessão cada vez maior com a memória e o passado, por outro. Dessa forma, o nosso "fardo da história" talvez seja exatamente a percepção dominante, no Ocidente ao menos, de que ela tenha chegado ao fim. Como podemos, diante desse suposto fenecimento, tentar recuperar a historicidade de um presente que, no entendimento de Fredric Jameson (2003; 2015a), a reprime constantemente?

Igualmente, o "fardo da história" também pode ser concebido como o peso nos colocado pela reificação da historiografia disciplinada e seus diversos dispositivos, talvez já não mais tão adequados à nova ordem em que vivemos. Em outras palavras, o "fim da temporalidade", ideia que esmiuçarei abaixo, abre espaço a uma reflexão mais ampla sobre a historicidade da própria disciplina, muitas vezes reprimida por seus praticantes, e os impasses nos dados por este "novo tempo do mundo" (ARANTES, 2014). Gostando ou não disso, o fato é que o "fim da história" não é somente uma provocação barata levada a cabo por intelectuais a soldo dos interesses dominantes, embora também o seja, mas pode ser pensada como o reconhecimento de que, histórica como é, a historiografia disciplinada possivelmente tenha chegado a um limite político bastante complicado. No meu entendimento, e espero deixar isto mais claro nas linhas que seguem, o nosso encarceramento no presente nos obriga a desnudar criticamente as políticas do tempo e 
homens no tempo", o tempo e o lugar da história nele constituíram-se como dois dos "não-ditos" que ajudaram a lhe dar legitimidade política, por um lado, e a naturalizá-la como algo objetivo e universal, por outro.

Isso significa que, diante disso tudo, a historiografia talvez precise se indisciplinar, ou mesmo se "desdisciplinarizar", isto é, alterar significativamente suas identidades e normas disciplinares ${ }^{1}$, especialmente aquelas que sustentam um "passadismo" que não aparenta ser mais factível ou convincente e que, muitas vezes, apenas a paralisa intelectualmente. O dilema notado por White em 1966 continua, portanto, pleno de sentido: diante de um presente que se recusa a iluminar-se, como é o nosso, a história pode ser um instrumento fundamental para sua observação criativa e crítica - somente, contudo, se souber encarar e administrar seus próprios fardos.

\section{O presente que não passa}

Expliquemos, portanto, a ideia, até aqui só esboçada, de "fim da temporalidade". É evidente que ela não implica na afirmação descabida de que o tempo tenha se consumado, mas sim na percepção de que alguns modos de experimentá-lo e representálo se transformaram radicalmente, especialmente a partir da segunda metade do século XX. Como já aduziram uma série de autores e autoras, este processo teve dois âmbitos específicos: de um lado, as diversas e até então inimagináveis catástrofes da centúria passada, também possibilitadas por um desenvolvimento tecnológico sem precedentes, lançaram sombras indeléveis à crença oitocentista no progresso inexorável e, portanto,

\footnotetext{
${ }^{1}$ Segundo Dominick LaCapra (2004, p. 7), "identidade disciplinar" pode ser definida como "uma forma específica de identidade profissional e intelectual que sub-repticiamente informa análises e críticas de certos fenômenos" e que, por sua vez, decide o que pode ser aceito como pertencendo ou não pertencendo ao campo disciplinar "legítimo". Nesse caso, em diversos debates, como, por exemplo, aqueles envolvendo o dito "pós-modernismo" e seu "impacto' na historiografia, a demarcação do que podia ser considerado como "história" era mais importante do que o engajamento efetivo com as discussões teóricas em questão. Com isso, alguns problemas eram interditados de antemão, justamente por não serem considerados "históricos" por aqueles e aquelas que hegemonizavam a definição da identidade disciplinar da historiografia.
} 
a demandas ensandecidas por instantaneidade e rapidez, contraindo-o a presentes mais e mais autocontidos, mas apartados uns dos outros. Segundo Jameson (2015a, p. 128), que cunhou o termo, o fim da temporalidade pode, então, ser assim definido como:

Una pérdida de historicidad existencial pero también colectiva, de tal modo que el futuro se desvanece como impensable o inimaginable mientras que el pasado se convierte en imágenes polvorientas al estilo de Hollywood de actores con pelucas y cosas parecidas. (2015a, p. 128)

Perdidos entre futuros inimagináveis e passados evanescentes, estamos, no entendimento do crítico norte-americano, "encarcerados no presente", com o sentimento generalizado de que a história, a grande imaginação moderna por excelência, aparentemente não tem mais relevância para e nas sociedades contemporâneas. Nas palavras de Hartog (2017, p. 25): “com o fim do século XX, a história parece ter passado de toda poderosa a impotente. Por certo, seus altares são frequentados, mas seus servidores, muitos pelo mundo, parecem ter perdido a fé."

Diante disto, neste vagar fantasmagórico do presente, nossos passados teriam diversas outras formas que não necessariamente "históricas": para Amy Elias (2001), seriam desejos palpáveis, mas inalcançáveis; na visão de Jameson (1984), não passariam de pastiches com pouca ou nenhuma capacidade de intervenção crítica no e para o presente; e, finalmente, para Hartog (2017) seriam codificados a partir da obsessão contemporânea com “patrimônio", “comemoração” e a "memória”. Eis, portanto, uma das grandes ironias percebidas por todos esses intelectuais: apesar de uma volta generalizada ao pretérito, por assim dizer, parecemos incapazes de historicizar nosso mundo de forma minimamente satisfatória. O "pesadelo da história" que um dia desesperou Stephen Dedalus, seria, neste contexto, justamente a impossibilidade de realizá-la. Aqui, como bem escreveram Manuel Cruz (2014, p. 207-230) e Hartog (2017, p. 9-30), é a ausência de futuro que complica nossa relação com ela: se estamos presos a um sempiterno presente, em um tipo de déjà-vu perpétuo, por que deveríamos nos importar com as "lições da história”, quaisquer que sejam elas? 
Esta impressão de que não há "nada mais a aprender com a história” é um efeito, portanto, da erosão das nossas imaginações futuristas - o que, por sua vez, nos impele ainda mais ao passado, numa dialética que, ao fim e ao cabo, só aumenta nossa sensação de prisão no presente. Na compreensão de Perry Anderson (2011), esta volta ao passado equivaleria a uma tentativa desesperada de "nos acordar para a história, em um tempo em que qualquer senso real dela morreu". Tal qual Austerlitz, o notório personagem errante de W. G. Sebald, a buscamos apenas para confirmar nossos temores de que ela feneceu; perambulamos à procura de seus resquícios somente para termos certeza de sua incompreensão ou, in extremis, de sua inutilidade. Nesse contexto, como escreveu Amy Elias (2001, p. xvii-xviii), a história torna-se:

Não um conhecimento que aprendemos e "possuímos" assim que o aprendemos; ao contrário, (...), ela é algo que não podemos aprender, algo que somente podemos desejar. Cumprindo a profecia de Marx de que sob o capitalismo "tudo que é sólido se desmancha no ar", a história transforma-se num processo ao invés de um bloco estável de conhecimento. ${ }^{2}$

A instabilidade percebida pela autora é ampliada, de acordo com a análise de White (2010, p. 304-317), pela impressão de que o passado não nos é mais "acessível”, artifício fundamental da crença moderna na história, seja pela impossibilidade de narrativizarmos os eventos traumáticos das últimas centúrias ${ }^{3}$, seja pela opacidade paradoxalmente produzida pela superprodução de documentos e imagens sobre ele à

\footnotetext{
${ }^{2}$ Not a knowledge we learn and "own" once we learn it; rather, (...) it is something we know we can't learn, something we can only desire. Fulfilling Marx's prophecy that under capitalism "all that is solid melts into air", history becomes a process rather than a stable block of knowldege.

${ }^{3}$ Segundo White (1999, p. 66-85)), os eventos modernistas do século XX e XXI são caracterizados pelo seu caráter "inimaginável" anteriormente ao amplo desenvolvimento econômico e tecnológico destas centúrias; acontecimentos como o Holocausto, as duas guerras mundiais, a explosão das bombas atômicas em Hiroshima e Nagasaki, a destruição acelerada do meio-ambiente, o atentado contra o World Trade Center e os genocídios "científicos" e "racionais" destes períodos funcionariam, dessa maneira, como "traumas debilitantes" na consciência histórica e política de determinados grupos. Consequentemente, seus sentidos permaneceriam ambíguos e difíceis de precisar, assim como desafiariam as técnicas tradicionais de representação da historiografia disciplinada (contextualização e textualização, por exemplo). Por isso, insiste White, deveríamos encontrar outras maneiras de representá-los. Embora concorde com essa conceitualização, adicionaria a ela, ainda, outros dois fenômenos: a escravidão africana nas Américas e a conquista do mesmo continente pelos europeus, por causa da extensão de seus efeitos no tempo (são passados que não passam) e do trauma, mesmo que denegado por certos sujeitos, que acarretaram para diversas comunidades. Não custa lembrar ainda, que, no caso específico da escravização de seres humanos no Novo Mundo, a racionalidade era tipicamente moderna e capitalista. Sobre isso, ver GRÜNER, 2010.
} 
ainda mais nossa sensação de isolamento em relação a períodos mais remotos. Já no segundo caso, a abundância de registros considerados "históricos" opera como uma "máscara" que mais oculta do que revela algo sobre aquilo a que pretendem referir-se. $\mathrm{O}$ que antes era imaginado como tendo alguma organicidade, mesmo que nem sempre convincente $^{4}$, agora aparece, segundo White, como simples virtualidade. Desta forma, o fundacionalismo que sustentava a história vê-se transformado em algo extremamente frágil, quando não delirante.

No entanto, esta busca por fundações sólidas, na indisponibilidade da história, faz com que o passado circule muito mais como "memória" ou "nostalgia", com pouca ou nenhuma mediação crítica, contudo. De acordo com Geoff Eley (2011, p. 556):

Representações do passado, pessoais e coletivas, privadas e públicas, comerciais e inspiradora, tornam-se tanto terapia quanto distração, uma fonte de familiaridade e previsibilidade, mesmo que o presente deixe de ser confiável. Tal nostalgia reflete um desejo pelo familiar, pela fixação e retenção dos delineamentos de mundos em movimento desconcertante, de pontos de referência que estão desaparecendo e seguranças que foram perturbadas. ${ }^{5}$

"Memória" e "nostalgia" podem, assim, ser pensadas tanto como tentativas de se “reencantar o presente”, para usar as palavras de Kerwin Klein (2014, p. 112-137), quanto de se "sacralizar o passado". Destarte, não é surpreendente, aos olhos do historiador norte-americano, que vários discursos e práticas de memória, apesar de suas diferenças,

\footnotetext{
${ }^{4}$ Neste caso, não foi o "passado" que se "tornou obscuro", como se anteriormente transparente fosse, mas nossas percepções dele que se alteraram substantivamente, ou seja, de uma crença em sua acessibilidade mais ou menos fácil, fundamental para a conformação da disciplina histórica, passamos à ideia de que ele é agora "opaco", "inacessível”, "incognoscível” e/ou “irrepresentável”. Na visão desse autor, contudo, o passado nunca possuiu uma relação "orgânica" com o presente em si mesmo - ela é sempre limitada pelas formas como determinado período imagina e organiza as relações entre estes âmbitos temporais, que são, por seu turno, eminentemente políticas.

${ }^{5}$ Representations of the past, personal and collective, private and public, commercial and uplifting, become both therapy and distraction, a source of familiarity and predictability, even as the actual ground of the present ceases to be reliable. Such nostalgia spells the desire for holding onto the familiar, for fixing and retaining the lineaments of worlds disconcertingly in motion, of landmarks that are disappearing and securities that are unsettled.
} 

desindustrialização massiva dos países do centro capitalista, ameaçavam com a destruição de tradições culturais, vínculos históricos e identidades centenárias, a memória respondia com suas naturalizações; se, de outra forma, a "história" era pensada como um simples efeito do colonialismo ou uma acumulação sem fim de traumas e catástrofes, a memória emergia como algo libertador e fundamental para a redenção dos horrores de antanho (KLEIN, 2014, p. 136-137).

É evidente que nem todas as práticas e discursos de memória têm tais consequências, assim como não podemos negar suas importâncias em determinadas situações - especialmente em países dados a uma obstinada amnésia, como é o caso do Brasil. No entanto, na análise precisa de Enzo Traverso, trabalhos de memória não acompanhados de perspectivas autocríticas ou transcendentes podem gerar ou uma melancolia paralisante e politicamente contraproducente ou uma deferência à nostalgia pura e simples, algo igualmente perigoso - nesses casos sofreríamos, nas palavras de Dominick LaCapra (2000, p. 52), uma “overdose do antídoto". 6 Quando toda e qualquer ruptura é refigurada como inevitavelmente levando à catástrofe, em uma espécie de script histórico já dado de antemão, então não existe possibilidade de concebermos quaisquer mudanças mais radicais em relação àquilo que aí está. Nessa perspectiva, na análise de Eley (2011, p. 558-559), estas linguagens e práticas espetacularizam o sofrimento e a injustiça passados e dificultam a apreensão daquilo que ele chama de “ideais positivos de autorrealização humana e emancipação social”, fundamentais para a ação política no presente. Isso acarreta um duplo movimento: por um lado, a separação dos horrores de ontem passado dos de hoje, com a magnificação excessiva dos primeiros e, por outro, a autocongratulação deste mesmo presente, imaginado como

\footnotetext{
${ }^{6}$ Segundo Traverso (2016, p. 18-28), estes são dois dos principais impasses vividos pela esquerda política nos dias de hoje: de um lado, uma melancolia advinda do sentimento de que o tempo das utopias é passé e, de outro, a nostalgia, cada vez mais exacerbada, pelos grandes movimentos de massas e esperanças da era industrial, dada a ausência de projetos radicais minimamente factíveis. Por isso, para o autor italiano, e eu tendo a concordar com ele, a enorme crise que parece se abater nas hostes progressistas, com raras exceções, Ocidente afora, mesmo diante da decepção de enormes setores da população com o neoliberalismo rampante e suas consequências sociais mais graves.
} 
qualitativamente melhor do que aquilo que o antecedeu. A atual instrumentalização da memória do Holocausto, por exemplo, como uma espécie de "religião civil" das democracias ocidentais, ilustra muito bem este processo: o que emerge dela não é necessariamente um reconhecimento do potencial holocaustal de nossa atualidade, mas a simples justaposição entre um passado maligno e um presente que, por sua vez, o teria superado definitivamente (LaCAPRA, 2009; BEVERNAGE, 2015). Afirmar que "mais memória" significa, portanto, um "melhor entendimento" de nosso próprio tempo é algo bastante ingênuo, pois corremos o risco, já aventado por Baldwin, de nos afogarmos no passado, ao contrário de utilizá-lo para a elaboração de visões alternativas para o futuro. Todos podem morrer por um excesso de memórias. Irineo Funes que o diga.

Por isso, o paradoxal sentimento de que o excesso mesmo de passados parece não contribuir para historicização alguma do presente, já que, no entendimento de Eley (2011, p. 557), eles, mesmo com todo o esforço de memorialização contemporâneo, acabam sendo evanescentes e, por isso, incapazes de prover a atualidade com a estabilidade que tanto buscam. Mais do que isso: não raro, na paisagem intelectual e cultural contemporânea, o tempo antes de agora é metaforizado como uma espécie de local turístico, uma ilha exótica ou uma terra encantada ${ }^{7}$, e tal "panorama de alteridade" acaba servindo aos propósitos de "viagens no tempo" cada vez mais desprovidas de potencial crítico. O passado é esvaziado de sua dimensão retrospectiva, fundamental, como afirma Jameson (1984, p. 66-67), a "qualquer reorientação de nossos futuros", para se transformar em uma "vasta coleção de imagens", um "multitudinário simulacro fotográfico" - e, acrescentaria eu, digital. O problema aqui, portanto, não é nem tanto o anacronismo, pois toda e qualquer relação com o passado envolve graus variados de anacronia, mas a aparente ausência mesma de tempo; não o "tempo fora do lugar" lamentado por Hamlet, mas os "lugares fora do tempo" do sempiterno presente:

\footnotetext{
${ }^{7}$ Não me parece coincidência, assim, que uma das historiadoras comercialmente mais bem-sucedidas do Brasil, Mary del Priore, busque vender suas obras a partir do "encantamento" que produziriam nos leitores e leitoras, convidados por ela a "um passeio no tempo". Na minha compreensão, tal postura sanciona uma visão domesticada e confortável do passado, pois retira seu poder crítico e capacidade de perturbação no presente. O pretérito imaginado por Del Priore é um local aonde se vai a passeio, para, mais tarde, se retornar para o conforto da atualidade, sem que esta necessariamente se veja confrontada pela jornada. Ver http://revistacult.uol.com.br/home/nao-se-democratiza-o-conhecimentofalando-empolado-e-discutindo-teorias-hermeticas/
} 


\begin{abstract}
Deste modo, imagens históricas são usadas no interesse do "pastiche", uma montagem achatada e ahistórica que existe não para possibilitar que as audiências pensem critica e historicamente sobre seu presente, mas para acabar com tal pensamento, deixando implícita a ideia de que a história não é nada mais do que uma série de figuras que podem ser colocadas em qualquer ordem, para criarem um efeito emocional no público consumidor. (ELIAS \& BURGESS, 2016, p. 6)
\end{abstract}

Em certo sentido, o que temos, portanto, é uma comodificação do passado em larga escala, auxiliada pelas novas tecnologias midiáticas, em que a satisfação instantânea de nossas ansiedades, por um lado, e o uso indiscriminado de citações, referências e justaposições de todos os tipos, por outro, nos fixam ao pretérito como "estátuas-de-sal" (CRUZ, 2014, p. 226). Neste processo, segundo Eley (2011, p. 557):

As novas tecnologias da informação e a mídia eletrônica de massas também fazem sua parte. $O$ processo da comodificação e comercialização da cultura, nas culturas consumidoras de entretenimento e demonstrações estilísticas, produzem uma economia pós-moderna de signos em que se torna impossível escapar à arbitrariedade móvel das imagens e citações históricas. (ELEY, 2011, p. $557)^{9}$

A impossibilidade de fuga dessa condição produz, deste modo, uma situação dúbia: tanto precisamos da "história", a qual recorremos constantemente das mais variadas formas, quanto reconhecemos sua duvidosa capacidade de explicar-nos algo, quando não de nos salvar deste "presente monstruoso". Com isso, reiteramos o sentimento de que existe uma quebra, talvez irreparável, entre o tempo em que vivemos e o antecedeu. Essa "quebra" constitui, assim, a própria redução do presente a si mesmo e sua dificuldade de auto-historicização. Desta forma, o "fardo da história" apontado por White em 1966 pode ser repensado não somente como o peso das "tradições mortas que oprimem o cérebro dos vivos" (MARX, 2011, p. 25), mas como o reconhecimento trágico de que estamos presos no tempo, comprimidos entre um passado que nos elude com sua multiplicidade de sentidos e um porvir talvez inalcançável.

${ }^{8}$ Thus historical images are used in the interest of "pastiche," a flattened, ahistorical montage that exists not to enable audiences to think critically and historically about their present but actually to shut down such thought, implying the idea that history is nothing more than a series of pictures that can be spliced together in any order in order to create an emotional effect for a purchasing public.

9 The new information technologies and electronic mass media also play their part. Processes of commodification and the commercialization of culture, in the consumer economies of entertainment and stylistic display, produce a postmodern economy of signs in which the mobile arbitrariness of historical imagery and citation becomes impossible to escape. 
Diante de tudo isso, como, a história pode ser recuperada, se é que pode? Quais podem ser nossas possibilidades mínimas de libertação deste "presente que engole a todos" (CRUZ, 2014, p. 230)? De que maneira podemos nos movimentar por estas paragens hodiernas repletas de nostalgias, memórias e do sentimento de que algo se rompeu irreversivelmente?

\section{Tempo e (in)disciplina}

Nessas condições, não é uma surpresa a "crise da história" diagnosticada de um modo ou de outro por diversos nomes importantes desde os anos 1990, pelo menos. Antes de ser o resultado de um insidioso ataque de "bárbaros" e "irracionais" pósmodernos $^{10}, \operatorname{com}$ suas tentativas de destruição do nobre edifício da civilização ocidental, ela pode ser considerada como um efeito desta outra crise, a do tempo. Já em 1992, Dipesh Chakrabarty, com lucidez ímpar, compreendeu que a aceleração temporal colocada pela ordem neoliberal vitoriosa impunha uma dificuldade tremenda aos historiadores e historiadoras, pois desafiava as políticas do tempo tradicionalmente favorecidas por eles e elas. Mas, ao contrário de vários de seus e suas colegas, que usavam a crítica ao "fim da história" como uma forma de reificação da ortodoxia disciplinar ${ }^{11}$, o indiano antevia uma necessidade mais profunda de se encarar o futuro da historiografia em outros termos que não aqueles herdados do século XIX (CHAKRABARTY, 1992, p. 56-64).

Como White, mas talvez sem a mesma gravitas, Chakrabarty identificava aquela já comentada quebra na relação entre passado e presente e as dificuldades da historiografia

\footnotetext{
${ }^{10}$ O mote da "irracionalidade", quando não da "barbárie", dos supostos "pós-modernos" foi recorrente ao longo dos debates teóricos das décadas de 1980 e 1990, quando historiadores e historiadoras com os mais diferentes posicionamentos teóricos e políticos se insurgiram contra os "bárbaros no portão", numa reação absolutamente desmesurada àquilo que era, acima de tudo, um debate teórico sobre os limites do conhecimento histórico. Com isso, na demonstração brilhante de LaCapra (2000; 2016), eles e elas visavam menos debater a sério as proposições dos ditos "pós-modernos", um significante vazio, do que interditar politicamente de antemão certas questões - foi o caso, aqui no Brasil, das exortações de Ciro Cardoso contra o "pós-modernismo" em suas mais diferentes formas, por exemplo. O resultado foi a criação de espantalhos que pouco ou nada tinham a ver com os problemas teóricos em questão e que transformaram o "pós-modernismo", e tudo associado com ele ("virada linguística", "desconstrução", "narrativismo", etc.), em uma figura "fantasmagórica" e "demoníaca" destinada a destruir a historiografia e, por consequência, a civilização ocidental (como se a segurança de uma decorresse evidentemente da saúde da outra...).

${ }^{11}$ Sobre isso, ver as excelentes análises de LaCapra (2000; 2004).
} 
"naturalmente" orientado em direção a um futuro desconhecido e com uma separação facilmente identificável entre as linhas temporais (LORENZ, 2014). Na medida em que a historiografia disciplinada insiste em tratar delas como se estáveis fossem, essa ofuscação complica suas políticas de tempo habituais: como já foi colocado acima, se não possuímos mais futuros, por que haveríamos de aprender qualquer coisa com o passado? Se ele não mais nos comunica nada, qual o motivo para continuarmos insistindo em sua importância para o presente? Não teríamos, por circunstâncias alheias à nossa vontade, chegado na tão temida "pós-história", aquele momento em que o presente se faria homocrônico ad aeternam?

Mais do que uma crise disciplinar a ser resolvida internamente, portanto, o dilema da historiografia disciplinada parece ser muito semelhante àquele identificado por Christa Wolf (2007, p. 226) entre o desajuste crescente entre as palavras que temos e os novos fenômenos que enfrentamos: ainda que, segundo ela, continuemos "a escrever da forma que estamos acostumados", "não podemos crer no que vemos. E não podemos expressar aquilo que já cremos". Trocando para os nossos termos: em grande medida, a historiografia disciplinada continua a operar do modo que está habituada e a não crer no que está vendo, mas, ao contrário do que colocou a escritora alemã, não parece, em que pesem importantes exceções, disposta a mudar suas próprias crenças. Somos recalcitrantes em admitir que determinadas formas disciplinares parecem ter se esgotado justamente porque o tempo que as viu nascer cambiou radicalmente.

Por isso, retomo o problema indicado por White ainda em 1966: como a historiografia pode nos ajudar, se é que pode, a enfrentar um presente que nos parece estranho e caótico, quando não incompreensível? Como, neste mundo em que temos passados evanescentes e imediatistas, pensar o problema da disciplina e de suas políticas do tempo? No que o "fim da temporalidade" pode, paradoxalmente, contribuir para a o nosso próprio papel na constituição de formas outras de se lidar com o tempo histórico? 
Em primeiro lugar, é fundamental que enfrentemos tais indagações sem a predisposição a naturalizar a própria disciplina. Tem sido essa a postura, por exemplo, de uma série de profissionais ${ }^{12}$, mesmo que bastante diversos entre si, que, diante de tudo que foi dito aqui, buscaram simplesmente reafirmar o papel da historiografia enquanto uma "ciência" pautada por "métodos" e "regras" seculares e, por esses motivos, supostamente mais competente em lidar com o passado do que outras formas. Dizer que "o ponto diferencial é que o historiador pode levar ao público um conhecimento mais crítico, mais reflexivo" (SÁ MOTTA, 2016, p. 326), por causa de seu trabalho a partir da "inquirição das fontes" e o uso do "método", ou que a história "elabora, argumentativamente e de forma metodicamente controlável, a explicação de ocorrências que se deram no passado" (MARTINS, 2006, p. 12) é continuar evadindo o problema central exposto por White já há cinquenta anos:

A história, tal como se costuma concebê-la é um tipo de acidente histórico, um produto de uma situação histórica específica, e de que, desfeitos os mal-entendidos que deram origem a essa situação, a história talvez perca sua condição de modo de pensamento autônomo e autolegitimador. (WHITE, 1994a, p. 41)

Nesse sentido, responder à crise com a simples reificação daquilo que herdamos do século XIX me parece um convite a permanecermos num beco sem saída. Afirmar que temos uma autoridade natural para lidar com o passado diante de todas as outras instâncias, pelo simples fato de assim o desejarmos, pode até acalantar nossos egos, mas não responderá ao dilema acima exposto. É preciso admitir, como Michel de Certeau já o fizera na década de 1980, que a historiografia disciplinada se transformou, bem ou mal, em mais uma das diversas formas e instituições que representam o passado em nossos dias. Não há escapatória a essa condição, simplesmente porque ela é inerente à busca humana por sentido. Diante do caos do processo histórico, e do absurdo que é estarmos aqui, neste lugar e neste tempo, os indivíduos tentam dar um sentido a suas vidas através de escolhas morais, estéticas e cognitivas que podem, inclusive, estar em franca contradição com as da disciplina histórica. Por conta de sua própria ausência, o pretérito é um lugar para a imaginação, quando não para a fantasia, e existe uma multiplicidade

\footnotetext{
${ }^{12}$ Dentre outros e outras, ver HUNT, 1999; APPLEBY, HUNT \& JACOB, 1994; FONTANA, 2004; AGUIRRE ROJAS, 2007; NOIRIEL, 1996 e MARTINS, 2006.
} 
e historiadores poderiam, por exemplo, ampliar sua compreensão sobre os usos variados e cambiantes do passado no presente, sem necessariamente pressuporem sua inferioridade àqueles da disciplina.

Uma “defesa da história" efetiva deveria, deste modo, se preocupar menos com os limites disciplinares, como se imutáveis fossem, do que com sua abertura a outras formas de historicização não só do passado, mas do presente. Reduzir a historiografia a uma simples busca pela verdade do pretérito, com a devida naturalização da pesquisa empírica e do modelo positivista-documental, como o chamou LaCapra, equivale a sua imobilização enquanto um instrumento crítico e a um apagamento de suas próprias tensões internas. De certo modo, foi exatamente isso que ocorreu durante a famigerada discussão sobre o não acontecimento da "virada linguística"13, quando historiadores e historiadoras, com raras exceções, estiveram mais preocupados em criar espantalhos teórico-políticos para justificar seu conservadorismo teórico do que em encarar as questões que lhes estavam sendo postas. Não foi coincidência, portanto, que ao "giro linguístico", seguiram outros que, de uma maneira ou outra, expungiam a linguagem e os problemas de representação de seus horizontes: a "virada arquivística" e o "retorno ao social", como se ambos houvessem sido abandonados, são exemplos disso (LaCAPRA, 2004; 2009; 2016). Igualmente, neste processo, a disciplina canibalizou o vocabulário da linguistic turn, com a popularização de termos como "narrativa", "discurso" e "desconstrução", esvaziando-os, contudo, do potencial crítico que carregavam e domesticando o que inicialmente fora um contundente chamado à indisciplina e à heresia

\footnotetext{
${ }^{13}$ Ao contrário do que postulam seus críticos, a "virada linguística" na história nunca foi hegemônica na disciplina, pelo contrário: mesmo durante os embates teóricos dos anos 1990, foram poucos os autores e autoras que a assumiram de fato. Em geral, como coloca LaCapra (2016), a disciplina manteve-se firmemente atrelada aos seus pressupostos mais conservadores, fazendo, no máximo, algumas concessões superficiais ao discurso associada à virada, mas não aos seus conteúdos mais radicais. A própria histeria coletiva daqueles anos, em que alguns e algumas imaginavam uma enorme conspiração "pós-moderna" para destruir a "racionalidade histórica", diz muito mais sobre os medos e ansiedades desses historiadores e historiadoras do que dos reais conteúdos da linguistic turn. Em resumo e repetindo, portanto: não houve uma virada linguística significativa na disciplina, somente uma reação, desmesurada em diversos casos, a um espantalho usado, por sua vez, para legitimar e reafirmar o conservadorismo disciplinar.
} 
p. 23), em confundir o âmbito empírico com o fim e a meta do conhecimento histórico como, aliás, ilustra muito bem a seguinte afirmação de outro famoso historiador brasileiro:

A moral da história (quiçá desmoralizada de antemão em tempos de relativismo pós-moderno radical chique) é que historiadores sociais servem melhor à causa da justiça social quando se empenham, modestamente, em fazer pesquisa histórica e tornar conhecidas as verdades que escavam nos arquivos. (CHALHOUB, 2009, p. 226)

O labor historiográfico é, assim, reduzido uma modesta "escavação de verdades nos arquivos", como se elas já estivessem dadas de antemão no próprio passado e sua constatação resumisse a finalidade da disciplina. Dessa maneira, não há como acreditar que nos afastamos daquela "ingenuidade metodológica deliberada" criticada por White (1994a, p. 40) há cinco décadas. Ela parece estar no cerne de algumas das definições contemporâneas sobre o que é ser um historiador ou historiadora.

Resgatar a disciplina como um lugar de tensões significa não reduzir normativamente a história à identidade disciplinar hegemônica em uma dada conjuntura e, através disto, pensá-la como algo em aberto, a despeito de regras, injunções e limites arbitrários e tenazmente definidos e defendidos. Nesse caso, é preciso, aqui, contrapor aquelas histórias que são explícitas quanto ao seu caráter representacional e às políticas que as sustentam àquelas que se fundam em preceitos disciplinares pouco ou nada problematizados ou que tomam a crítica a eles como sendo um "injustificável ataque" à história e sua "tradição milenar", numa espécie de repetição, ainda que sem o mesmo humor ou erudição, dos destemperados ataques de Thompson a Althusser ou de Ginzburg a White. Enquanto as primeiras tomam a crítica à disciplina como algo fundamental à prática e não hesitam em apontar suas limitações, as segundas assemelham-se a processos de excomunhões em que qualquer desvio do "realismo", seja ele o que for, é identificado como, na melhor das hipóteses, um erro a ser corrigido ou, na pior delas, inadmissível. É essa a postura, por exemplo, de autoras e autores tão variados como Josep Fontana, Richard Evans, Ciro Cardoso, Carlo Aguirre Rojas, Lynn Hunt e 
único e excludente de história aceitável que estabeleça a identidade profissional das historiadoras e historiadores" (LaCAPRA, 2009, p. 35). ${ }^{14}$

Uma história aberta, no meu entendimento, pode contribuir para imaginações que coloquem em questão o encerramento do presente nele mesmo. Para tanto, ela precisa levar a sério a sua condição como uma produtora de temporalidades. Dito de outro modo, a história nos ajuda na definição daquilo que é passado ou presente; como escreveu Lorenz, existe uma performatividade no discurso historiográfico que é seguidamente ocultada ou reprimida nas defesas conservadoras da disciplina. Uma periodização ou uma temporalização específica auxiliam na conformação da compreensão acerca dos "tempos em que vivemos" e é parte fundamental das lutas políticas que nos ajudam a definir a tessitura do próprio presente. Usando os termos de Peter Osborne (1995, p. 200), muito semelhantes, aliás, às ponderações de Jameson e White, é importante sempre nos fazermos as seguintes perguntas:

Como as práticas nas quais nos engajamos estruturam e produzem, permitem ou distorcem diferentes sentidos de tempo e possibilidade? Que tipos de experiência de história eles possibilitam ou impedem? Quais futuros eles asseguram? Estas são as questões às quais uma política do tempo deveria se interessar, interrogando as estruturas temporais sobre as possibilidades que elas encadeiam ou fecham, em modos temporais específicos. ${ }^{15}$

Sob essa perspectiva, a história pode oferecer perspectivas críticas do presente que visem desfamiliarizá-lo em relação a si mesmo e, com isso, propor outras imaginações sobre suas relações com o passado e com o futuro. Como lembrou Chakarbarty (1992, p. 58-60) há duas décadas, é justamente porque nosso mundo, independente do que dizem os defensores da apoteose neoliberal, é atravessado por conflitos e temporalidades

\footnotetext{
14 "There should not be a single dominant exclusionary model of acceptable history that establishes the professional identity of the historian".

${ }^{15}$ How do the practices in which we engage structure and produce, enable or distort, different senses of time and possibility? What kinds of experience of history do they make possible or impede? Whose futures do they ensure? These are the questions to which a politics of time would attend, interrogating temporal structures about the possibilities they encode or foreclose, in specific temporal modes.
} 

tempo", mas a "produtora de possibilidades no nível do tempo histórico" (OSBORNE, 1995, p. 200). Ao contrário de pressupor relações de continuidade e ruptura como dadas, ou seja, condições ontológicas do processo histórico, é preciso pensá-las como politizações do tempo que visam "dar um nome ao presente” (ELEY, 2007). Expressões aparentemente assertivas como "o passado que não passa" ou "o fim da história" não são, assim, somente o resultado de observações empiricamente verificáveis, embora também o sejam, mas de escolhas políticas que, por sua vez, "determinam a leitura e a interpretação do material" e definem inclusive o que pode ser pensado como um fato histórico, como já colocou Jameson (2007, p. 3). Sob esse aspecto, mesmo a afirmação de que vivemos no "fim da temporalidade" passa a ser não somente uma descrição empírica da realidade, embora perfeitamente factível, do que uma opção narrativa que visa dar um significado às peculiaridades a esta "nova ordem de existência histórica" (WHITE, 2010, p. 307) consolidada pelo capitalismo tardio. Por isso, a importância de narrativizações contrárias àquilo que nos é imposto como "óbvio" e "natural”, exatamente porque elas podem representar "temporalizações alternativas da 'história', que articulam as relações entre 'passado', 'presente' e 'futuro' de modos políticos e significativamente diferentes” (OSBORNE, 1995, p. 201).

Dessa maneira, ao invés de conceber o pretérito como uma corrente de causas, quaisquer que sejam, que inexoravelmente desembocaram no que aí está, deveríamos, na acepção de Robert Doran (2013, p. 12), a partir das ideias de White, “conceber nosso passado como um enorme conjunto de possibilidades das quais somos obrigados a escolher, mesmo que nem todas possibilidades sejam realizáveis no presente”. Isso nos forçaria a pensar na escrita da história, ou em outras formas de representá-la, como uma práxis que ajuda na formatação da realidade histórica mesma, para além de sua observação passiva, e, por isso, como um elemento fundamental para que nem o passado nem o presente nos sejam apresentados como prisões perpétuas e inescapáveis: 
Ao escolher nosso passado, escolhemos um presente. Usamos um para justificar o outro. Ao construir nosso presente, nos afirmarmos nossa liberdade; ao buscar justificação retroativa para ele em nosso passado, nós silenciosamente nos despimos da liberdade que nos permitiu sermos o que somos. (WHITE, 2010, p. 135)

"Escolher" não equivale a negar a facticidade do passado, muito menos em fazer tábula rasa dela, como ocorre em suas diversas apropriações nostálgicas ou em suas circulações como pastiche ou fetiche. ${ }^{17}$ No entanto, a resposta a isso não é simplesmente preencher o presente com mais e mais fatos sobre o passado, algo equivalente à hipertrofia de memória comentada acima, mas refigurá-lo de modo a denegar explicações e identificações definitivas no e para o próprio presente - que são justamente aquelas que sustentam nostalgias acríticas de toda ordem, por exemplo. Essa postura, segundo White (2010, p. 308-309), convida-nos a escapar dos fundacionalismos modernos e a encarar a história como sendo também um resultado das opções e ações que fazemos e tomamos em uma dada conjuntura, não simplesmente algo que sofremos passivamente algo, para finalmente voltarmos a ele, já dito por Baldwin em 1963: para que confrontemos nossa situação presente é necessário sabermos usar o passado de modo a transformá-lo em possibilidade, não em destino.

Sob este ângulo, a "história" adquire, portanto, uma conotação diferente do que a de uma construção de "origens" e "gêneses", a Ursprung nietzsche-foucaultiana, ou da devolução dos eventos a uma "integridade" supostamente violada por anacronismos diversos. ${ }^{18}$ Não há uma essência ou fundação imutável a ser encontrada aqui; encarar a historicidade sob este prisma é lidar com:

\footnotetext{
${ }^{16}$ In choosing our past, we choose a present. We use one to justify the other. By constructing our present, we assert our freedom; by seeking retroactive justification for it in our past, we silently strip ourselves of the freedom that has allowed us to become what we are.

${ }^{17}$ É sempre bom replicar o alerta de White (1994b, p. 114), muitas vezes tomado por um "relativista" que nega qualquer possibilidade de uma "verdade" histórica mínima: "isso não significa que não podemos recorrer distinguir entre a boa e a má historiografia, de vez que, para definir esta questão, sempre podemos recorrer a critérios como a responsabilidade perante as regras da evidência, a relativa inteireza do pormenor narrativo, a consistência lógica e assim por diante". Indisciplina, portanto, não é licenciosidade.

${ }^{18}$ Ainda que não nos exatos termos aqui expressos, a atual historiografia sobre capitalismo e escravidão parece estar se movendo exatamente nesta direção, ao demonstrar a dependência do capitalismo neoliberal de formas de exploração e organização do trabalho surgidas durante a Segunda Escravidão e apresentando-a, assim, como um dos elementos ocultos de nossa modernidade. Pode-se dizer,
} 
A ideia de que, ao invés de uma existir uma fundação ou substância pelas quais podemos determinar o sentido de eventos e processos históricos, a existência histórica é a única fundação que temos - o que, por sua vez, significa que, já que a história é um processo de formação e reformação contínuo, nós não temos uma fundação firme ou estável alguma. (WHITE, 2007, p. 223) $)^{19}$

\section{Coda}

Pensar que existem inúmeras formais possíveis de historicização, que nem sempre se preocupam exclusivamente com a "inquirição racional das fontes" ou com seu “controle metódico", é, por outro lado, tentar reinserir a história no mundo maior das Humanidades de onde surgiu e de onde ela deveria tirar inspiração - como, aliás, defenderam White, LaCapra, Jameson e uma série de outras autoras e autores. Ao invés de perder o tempo que não temos, diante dos ataques ideológicos e materiais cada vez mais graves aos quais estamos sendo submetidos $^{20}$, com discussões circulares e provincianas, como, por exemplo, as infindáveis exegeses sobre a "objetividade histórica" e a "diferença entre fato e ficção", historiadores e historiadoras poderiam se despir de suas inatingíveis pretensões científicas e usar a potencialidade poética e política da disciplina em prol de intervenções críticas mais contundentes, mesmo que limitadas pelas condições de nossa atualidade. ${ }^{21}$ Com isso, não poderíamos tentar, ao menos isso, questionar o fim da história, o fardo da temporalidade em que nos coube viver, reencontrando não só os vários passados que podem caber em nossos presentes, mas os diversos presentes que podem caber em nossos passados? E não poderíamos, ainda,

portanto, que autores como Rafael Bivar de Marquese, Leonardo Marques, Edward Baptist, Walter Johnson e Sven Beckert contribuem significativamente para a história do nosso presente, não somente para uma "releitura" do passado.

${ }^{19}$ The idea that, instead of there being a foundation or substance to which we can refer historical events and processes for the determination of their meaning, historical existence is itself the only foundation we have - which in turn means that, since history is a process of continual making and remaking, we have no stable or firm foundation at all.

20 Refiro-me aqui, obviamente, aos extensos cortes financeiros sofridos por programas e departamentos de Humanidades Ocidente afora e, no caso brasileiro, ao fenômeno autoritário e perverso do "Escola sem Partido", que vem ecoando em diversos setores políticos conservadores, em sua busca pela criminalização da liberdade de ensino e de cátedra, sob o pretexto, absolutamente ridículo, de se combater a suposta “doutrinação ideológica” realizada pelos professores e professoras de Ciências Humanas.

${ }^{21}$ É evidente que, sozinha, a historiografia nunca poderá fazer muita coisa. Dito de outro modo, nossas intervenções públicas não podem substituir outras formas de reflexão, organização e ação política. Acreditar o contrário é conferir à história um poder redentor e mobilizador que ela não tem. 
Deixemos a "aborrecida vigilância" exigida pela disciplina, para usar as astutas palavras do Comandante de Guimarães Rosa, para aqueles e aquelas com espírito mais dispostos a exercê-la, portanto. De minha parte, acredito que a história, como a vida, para parafrasear White (1994a, p. 63) uma última vez, "será mais bem vivida se não tiver um sentido único, mas muitos sentidos diferentes". Aproveitemos o fim como um começo.

\section{Referências}

ADORNO, Theodor. Negative dialectics. London: Routledge, 1973.

AGUIRRE ROJAS, Carlos. Antimanual do mau historiador: ou como se fazer uma boa história crítica? Londrina: Eduel, 2007.

ANDERSON, Perry. From progress to catastrophe.2011. Disponível em: $<$ https://www.Irb.co.uk/v33/n15/perry-anderson/from-progress-to-catastrophe>. Acesso em: 04 set. 2017.

APPLEBY, Joyce; JACOB, Margaret; HUNT, Lynn. Telling the truth about history. New York: Norton, 1994.

ARANTES, Paulo. O novo tempo do mundo. São Paulo: Boitempo, 2014.

BALDWIN, James. The fire next time. New York: Vintage International, 1993.

BEVERNAGE, Berber. The past is evil/evil is past: on retrospective politics, philosophy of history, and temporal manichaeism. History and theory. Middletown: Wesleyan University Press, v. 54, n. 3, p. 333-352, October 2015.

CERTEAU, Michel de. Heterologies: discourse on the other. Minneapolis: University of Minnesota Press, 1987.

CERTEAU, Michel de. A escrita da história. Rio de Janeiro: Forense Universitária, 2002. 
CHAKRABARTY, Dipesh. The death of history? historical consciousness and the culture of late capitalism. Public culture, Durham: Duke University Press, v. 4, n. 2, p. 47-65, Spring 1992.

CHALHOUB, Sidney. História social do trabalho, história pública. Perseu: história, memória e política, São Paulo: Fundação Perseu Abramo, v. 3, p. 219-228, 2009.

CIORAN, Emil. Silogismos da amargura. Rio de Janeiro: Rocco, 2011.

CRUZ, Manuel. Adiós, historia, adiós: el abandono del pasado en el mundo actual. Buenos Aires: Fondo de Cultura Economica, 2014.

DORAN, Robert. Editor's introduction: choosing the past: Hayden White and the philosophy of history. In: DORAN, Robert (Org.). Philosophy of history after Hayden White. New York/London: Bloomsbury, 2013.

ELEY, Geoff. Historicizing the global, politicizing capital: giving the present a name. History workshop journal, Oxford: Oxford University Press, v. 63, Issue 1, n. 1, p. 154-188, March 2007.

ELEY, Geoff. The past under erasure? history, memory, and the contemporary. Journal of contemporary history, London: Sage Publications, v. 46, n. 3, p. 555-573, July 2011.

ELIAS, Amy. Sublime desire: history and post-1960s fiction. Baltimore: The Johns Hopkins University Press, 2001.

ELIAS, Amy; BURGESS, Joel. Introduction: time studies today. In: ELIAS, Amy; BURGESS, Joel (Orgs.). Time: a vocabulary for the presente. New York: NYU Press, 2016.

FONTANA, Josep. A história dos homens. Bauru: Edusc, 2004.

GRÜNER, Eduardo. La oscuridad y las luces: capitalismo, cultura, revolución. Buenos Aires: Edhasa, 2010.

HARTOG, François. Crer em história. Belo Horizonte: Editora Autêntica, 2017.

HUNT, Lynn; BONNEL, Victoria. Introduction. In: HUNT, Lynn; BONNELL, Victoria; BIERNACKI, Richard. Beyond the cultural turn: new directions in the study of society and culture. Berkeley: University of California Press, 1999. p. 1-34. 
JAMESON, Fredric. The end of temporality. In:
Chicago, v. 29, n. 4, p. 695-718, Summer 2003.

JAMESON, Fredric. Late marxism: adorno or the persistence of the dialectic. London: Verso Books, 2007.

JAMESON. Fredric. La estética de la singularidad. New left review (español), Madrid: Traficantes de Sueños, n. 92, p. 109-41, 2015 a.

KLEIN, Kerwin Lee. On the emergence of memory in historical discourse. In: From history to theory. Berkeley: University of California Press, 2014.

LaCAPRA, Dominick. History and reading. Ithaca: Cornell University Press, 2000.

LaCAPRA, Dominick. History in transit: experience, identity, critical theory. Ithaca: Cornell University Press, 2004.

LaCAPRA, Dominick. History and its limits: human, animal, violence. Ithaca: Cornell University Press, 2009.

LaCAPRA, Dominick. What is history? What is literature? In: History and theory Middletown: Wesleyan University Press, vol. 56, n. 1, p. 98-113, 2016.

LORENZ, Chris. Blurred lines: history, memory and the experience of time. In: International journal for history, culture and modernity. Stichting International Journal for History, Culture and Modernity, v. 2, n. 1, p. 43-62, 2014.

MARTINS, Estevão Rezende. História e teoria na era dos extremos. Fênix (Uberlândia), Uberlândia: UFU, v. 3, n.2, p. 1-19, 2006.

MARX, Karl. O dezoito de brumário de Luis Bonaparte. São Paulo: Boitempo, 2011.

NOIRIEL, Gerárd. Sur la “crise de l'histoire”. Paris: Gallimard, 1996.

OSBORNE, Peter. The politics of time: avant-garde and modernity. London: Verso Books, 1995. 
SÁ MOTTA, Rodrigo Patto. Os lugares dos historiadores e da história na sociedade brasileira: conferência de abertura do XXVIII Simpósio Nacional de História, Florianópolis. In: História da historiografia. Mariana: UFOP, v. 22, p. 321-335, 2016.

TRAVERSO, Enzo. Left-wing Melancholia: marxism, history and memory. New York: Columbia University Press, 2016.

WHITE, Hayden. Afterword: manifesto time. In: MORGAN, Susan; MUNSLOW, Alun \& JENKINS, Keith (org.). Manifestos for History. London: Routldege, 2007. p. 220-231

WHITE, Hayden. O fardo da história. In: Trópicos do discurso: ensaios de crítica cultural. São Paulo: Edusp, 1994a. p. 39-64.

WHITE, Hayden. O texto histórico como artefato literário. In: Trópicos do discurso: ensaios de crítica cultural. São Paulo: Edusp, 1994b. p. 97-116.

WHITE, Hayden. The modernist event. In: Figural realism: studies on the mimesis effect. Baltimore: The Johns Hopkins University Press, 1999.

WHITE, Hayden. What is a historical system? In: The fiction of narrative: essas on history, literature and theory, 1957-2007. Baltimore: The Johns Hopkins University Press, 2010.

WHITE, Hayden. Postmodernism and textual anxieties. In: The fiction of narrative: essas on history, literature and theory, 1957-2007. Baltimore: The Johns Hopkins University Press, 2010.

WOLF, Christa. Cassandra. São Paulo: Estação Liberdade, 2007. 